\title{
THE IMPACT OF CHANGING THE GRANULARITY OF PREFERENCE-INTENSITY INFORMATION ON THE ONLINE COMPENSATION ELECTION ${ }^{1}$
}

\author{
Roumen Vragov ${ }^{1}$ and Nanda Kumar ${ }^{2}$ \\ ${ }^{1}$ Queensborough Community College, CUNY, $2220556^{\text {th }}$ Ave, Bayside, NY 11364, USA \\ ${ }^{2}$ Baruch College, CUNY, 1 Bernard Baruch Way, New York, NY 10036, USA
}

\begin{abstract}
This study investigates the effect of a change in the granularity of preference intensity information available to voters on their voting behavior in an online referendum with options to express preference intensities and receive compensation. We find that a decrease in the granularity of the real preference intensity information about others does not affect voting behavior and the referendum's compensation outcomes We discuss the implications of these results and possible future directions for research.
\end{abstract}

\section{KEYWORDS}

Information Granularity, E-Government, Digital Voting Mechanisms, Group Decision-Making, Public Goods, Semi-Field Experiment

\section{INTRODUCTION}

The Compensation election is a referendum-like new electronic voting mechanism that allows participants to express the intensity of their preferences and also to get compensated in case the alternative they vote for is not chosen. The intuition behind this mechanism has been expressed as early as the beginning of the $19^{\text {th }}$ century by Wicksell (1896/1967) who observes that there might be a way to improve the results of referenda for every referendum participant if the voting mechanism allows some way in which the winners in the referendum can compensate the losers. Jumping to modern times, Smith (2004) provides a detailed description of procedure that can support such a referendum in practice. Here is an example of how the procedure works. Suppose that citizens A, B, and C are considering building a public stadium in their small community and they all start with the same initial endowment of $10^{2}$. The endowment can represent income, property and anything else of value that the individual possesses. Suppose further that the net financial effect of building the stadium to $\mathrm{A}$ is 2 , to $\mathrm{B}$ is 2 and to $\mathrm{C}$ is -10 . If the citizens vote to build a stadium using majority voting, A \& B will both vote "Yes" because they gain from the proposal and C will vote "No" because s/he looses. The stadium will be built and that would result in A gaining 2 for a total final endowment of 12; B gaining 2 for a total final endowment of 12, and $\mathrm{C}$ loosing 10 for a total final endowment of 0 . The net social gain: $2+2-10=-6$ is negative and so the outcome does not increase or at least keep the social value unchanged. It could be argued also that the outcome is unjust since the citizens started on an equal financial footing but ended up with a skewed income distribution. Under the procedure proposed by Smith it is possible that A votes 1 , B votes 1 , and $C$ votes -6 . Since the sum of votes is negative, the stadium will not be built but $\mathrm{C}$ has to pay 1 to $\mathrm{A}$ and 1 to $\mathrm{B}$ because the alternative they voted for is not chosen. In this case A gains $1, \mathrm{~B}$ gains 1 , and $\mathrm{C}$ gains 4 . The net social gain is 6 , and the final income distribution will be less skewed than under majority voting.

\footnotetext{
${ }^{1}$ This study was funded by a PSC-CUNY research grant and the Eugene Lang faculty research program

${ }^{2} \mathrm{~A}$ specific currency is not selected on purpose to keep the example more general.
} 
A laboratory test of an electronic implementation of the above procedure is presented in Oprea et. al. (2007) and an experimental test of an online version of the mechanism is presented in Vragov \& Kumar (2019). The laboratory test of the mechanism in small groups of participants with synchronous voting has shown that mechanism participants tend to reveal a fraction of their preference intensity in voting. This, combined with the compensation procedure, has resulted in improved social value and in more equitable voting outcomes among subjects in the laboratory (Oprea et. al, 2007). Vragov \& Kumar (2019) find that the online version of the mechanism needs adjustment of some of the design parameters in order for the mechanism to perform satisfactorily. In this study we decide to explore one of the factors that affects the performance of any group decision-making mechanism: the amount of information that individual participants have about their decision-making environment (Blackwell, 1951, Ballou et. al., 2010, Chengalur-Smith et. al., 1999). We specifically focus on information granularity and see how changes in the level of detail of the information provided to participants in the referendum mechanism about the preference intensity of others affect individual voting behavior. We are choosing to study this issue because we think that under naturally occurring circumstances citizens will most likely have less granular information about other individuals' real preference intensities than that provided to the subjects in Oprea et. al.'s laboratory experiment and Vragov \& Kumar's semi-field experiment. Thus we test the performance of a mechanism that is a little more realistic in terms of implementation than the ones tested in the two studies mentioned above. We consider this to be an important policy and design question since a long stream of previous literature on data-driven information dashboards has shown that the amount of information citizens receive has an impact on their actions (Matheus et. al, 2018, Abelson et. al., 2004, Bertot et. al., 2010). Thus our main research question is: "How would a decrease in the granularity of preference intensity information about other participants affect individual voting behavior and each individual's gains from participating in the referendum?"

To answer this question we use design science theory and a semi-field experiment. Vragov \& Kumar's study acts as our baseline and our semi-field experiment represents a new treatment in which the granularity of the information each individual receives about the real preference intensities of other referendum participants is lower. We find that a decrease in the information granularity of the preference intensity information that subjects have at the beginning of the referendum does not have a significant impact on individual voting behavior. This is good news in terms of practical implications since it shows that even if participants do not possess as detailed information about the preference intensities of others as in the laboratory study, their behavior and earnings remain relatively unaffected.

\section{LITERATURE REVIEW}

Information granularity is one of the important dimensions of information. The term first originated in the data-mining literature to describe the level of detail contained in a database or a data warehouse. With the help of a database tool managers can drill down the data starting from the very general level (for example annual sales in a country) to a very detailed level (monthly sales in a specific region of this country) or vice versa (Baltzan, 2017). In general the ability to see information at various levels of granularity is expected to improve data analysis and the ability of a manager to make better business decisions (Peng et. al, 2007, Chengalur-Smith et. al., 1999) and also improve board oversight (Ballou, et. al., 2010).

More detailed studies on the effect of granularity on decision-making are lacking. For any decision-making task the background information provided has to be at the appropriate level of detail but it is not clear how to determine which level of detail is the most appropriate. For example Peng et, al. (2007) discuss situations when, because of search costs, decision-makers are not always able to reach the appropriate level of detail with drill down which might result in suboptimal choices.

Information granularity and information transparency have also been discussed in the electronic government literature as they relate to the implementation and usage of information dashboards for smart cities (Matheus et. al., 2018). The general consensus is that an increase in information transparency and granularity can improve citizen engagement (Abelson et. al., 2004), can help fight government corruption (Bertot et. al., 2010), and can improve government decision-making (Dawes \& Helbig, 2010)

There is also a considerable stream of research in the accounting literature related to public disclosure of financial information (see Banerjee \& Maier, 2016, for a review). The articles in this research stream 
describe situations in which groups of individuals or firms face uncertainty about the decision environment combined with uncertainty about the strategies of other individuals or firms. The situation requires some sort of coordination between these individuals or firms in order for the optimal outcome to be realized. The articles show both theoretically and experimentally that the results of such situations could be influenced both positively and negatively when more information is provided to the individuals or firms. In some cases, when individuals are given more public information, they place more importance on the public information than on their private information, which results in a coordination failure and sub-optimal outcomes. Such strategic situations are characterized by multiple equilibria, some of which are better and some of which are worse after the introduction of more information, and it is impossible to determine a priori which of these equilibria will occur (Anctil et. al, 2004). The referendum mechanism described here shares some of the general features of the situations modeled in this stream of literature because 1) there is uncertainty about individual preference intensities of others and the outcome of the referendum, 2) each individual receives private information (the individual's personal preference intensity for each alternative) and also public information (the distribution of preference intensities of other individuals before the referendum, and the results of the referendum) and 3) individuals have to implicitly coordinate their bids in order to pick the better of the two alternatives. Because of these strategic features of the mechanism studies here the outcomes when changing information granularity could go either way.

\section{DESIGN SCIENCE METHODOLOGY AND SOME THEORETICAL ISSUES}

There is currently no widely acceptable theoretical model that can predict the effect of change in information granularity on individual voting behavior under a referendum mechanism that involves the options of expressing preference intensities and compensation. Fortunately we have an experimental baseline provided by Vragov \& Kumar (2019) so we can adopt the exploratory design science approach to investigate changes in human behavior by changing only one parameter in their design and analyzing the results. The design science theoretical approach has been discussed widely in the literature (see March \& Smith, 1995; Hevner et. al., 2004; Gregor, 2006; Peffers et. al., 2007; Goes, 2013, Lang et. al, 2016). Under this approach theoretical concepts and findings from the literature are used to guide the discussion of theoretical relationships among variables of interest that structure our voting mechanism design. The discussion is used to present plausible working hypotheses, which are more akin to open research questions than theoretical predictions, to indicate that the outcome is exploratory and could very well go either way. The real utility of this approach is in the practical implications of its findings since they increase our knowledge about a mechanisms that could readily be applied in practice to solve real problems (e.g. designing a new airplane is so complex that the effect of every feature cannot be predicted theoretically, however a new model airplane can be built and tested in a wind tunnel before it is used in practice on a daily basis).

Normally one would expect that in order to formulate an optimal participation strategy the individual voter would need as much information as possible about the real preference intensities of other individuals. Having less information would probably result in an individual having a harder time finding the optimal strategy. Therefore our working hypothesis is that we expect a decrease in granularity of the information available to an individual about the distribution of real preference intensities of other individuals to have a negative effect on individual earnings.

\section{EXPERIMENTAL DESIGN}

In our experimental design we follow exactly the procedures described in Vragov \& Kumar (2019). Subjects can $\log$ in to the voting system online from any Internet-enabled computer, read the instructions, and participate in the voting process from anywhere and anytime during the day. There are four referenda per day, and the experiment lasts 5 consecutive days. After the experiment is over subjects come to our office to collect their experimental earnings. During the time of the experiment subjects are not aware of who and how many the remaining participants in the referendum are and when they make their decisions. Subjects see the results of the voting in each referendum from the first day on the second day and so on. 
We also copy the experimental environment from Vragov \& Kumar (2019) as much as possible. Subjects make voting decisions, which eventually determine which alternative from two possible alternatives will be chosen. Every subject $i$ is assigned a preference intensity for each of the two alternatives in these four different referenda A, B, C, D that does not change from day to day. For simplicity, subject preference intensities are normalized so that if subject $i$ prefers alternative 1 in referendum $\mathrm{R}\{\mathrm{A}, \mathrm{B}, \mathrm{C}, \mathrm{D}\}$, then $i$ 's preference intensity for alternative 1 is positive and $i$ 's preference intensity for alternative 2 is 0 . Thus a subject always has a preference intensity of 0 for one alternative and a positive preference intensity for the other alternative. The positive preference intensities for all subjects are distributed according to a normal distribution. We use the exact same draws as in Vragov \& Kumar (2019)

Every subject $i$ has an assigned preference intensity of $v_{i}{ }^{K}$ and submits a vote of $b_{i}{ }^{K}$ for alternative $K \in\{\mathrm{A} 1$, A2, B1, B2, C1, C2, D1, D2\}. Subjects are allowed to vote only on one of the two alternatives in each referendum. Let's use $-K$ to represent the alternative complementary to alternative $K$. The winning alternative is determined by the sum of the votes for the two alternatives in each referendum. The alternative which has a larger sum of votes is the winning alternative. In the special case of a tie, the winning alternative is chosen at random with a flip of a coin. If individual $i$ votes for alternative $\mathrm{K}$ and $\mathrm{W}$ is the winning alternative, then the earnings to subject $i$ in a referendum are

$\pi_{i}=\left\{\begin{array}{ccc}v_{i}^{K}-b_{i}^{K} & \text { if } & W=K \\ v_{i}^{-K}+b_{i}^{K} & \text { if } & W=-K\end{array}\right.$

Subjects' earnings are summed over all referenda (four per day) and all five days of the experiment and then subjects are paid their total earnings. If a subject's total is negative, then the subject receives only the experiment participation fee of $\$ 5.00$.

From equation (1) it is clear that an individual's earnings are always positive as long as the individual votes for his/her preferred alternative and his/her vote is lower than his/her preference intensity (or value). The individual risks bankruptcy if s/he decides to bid above value or bid for the 0 alternative. The bid limit is equal to $\$ 9$, which is the highest possible value among the value draws. Thus if a subject is consistently voting for the alternative which s/he does not prefer, the subject could still go bankrupt but is allowed to stay in the experiment until the experiment is over. All of the described features of the voting mechanism are borrowed from Vragov \& Kumar (2019)

We investigate two possible levels of granularity related to the information that the mechanism participants receive about the preferences of others.

Level 1: Describing the distribution of the sum of preference intensities for both alternatives

Level 2: Describing the distribution of the preference intensities within the population.

Oprea et. al (2007) and Vragov \& Kumar (2019) use Level 2 granularity. We implement Level 1 granularity and we test for treatment effects.

The referendum participants' preference intensities are drawn from a normal distribution with different means for each referendum type. There are multiple ways in which this preference intensity information can be relayed to the referendum participants. The lowest possible level of granularity is to provide information to the referendum participants only about the expected sum of all participants' preference intensities. Next follows an example of how we specify this in the instructions:

Level 1:

"The sum of all values for alternative A1 is randomly chosen between $\mathrm{X}$ and $\mathrm{Y}^{3}$ and the sum of all values for alternative A2 is randomly chosen between P and Q."

The way that information is provided in the baseline study by Vragov \& Kumar (2019) has a higher level of granularity. Next follows an example of how they specify this in their instructions:

Level 2: A2.

"On average $\mathrm{A} \%$ of the participants prefer alternative $\mathrm{A} 1$ and $\mathrm{B} \%$ of the participants prefer alternative

Among those who prefer A1 values are distributed as following:

- $\mathrm{C} \%$ are between $\mathrm{D}$ and $\mathrm{E}$

- $\mathrm{F} \%$ are between $\mathrm{G}$ and $\mathrm{H}$

- $\mathrm{I} \%$ are between $\mathrm{J}$ and $\mathrm{K}$

\footnotetext{
${ }^{3}$ Preference intensities are drawn from a Normal distribution before the experiment starts. For simplicity In the instructions we try to provide better information about the actual draws themselves rather than the distribution from which they are drawn.
} 
Among those who prefer alternative A2 values are distributed as following:

- $\quad \mathrm{L} \%$ are between $\mathrm{M}$ and $\mathrm{N}$

- $\mathrm{O} \%$ are between $\mathrm{P}$ and $\mathrm{Q}$

- $\mathrm{R} \%$ are between $\mathrm{S}$ and $\mathrm{T}$ "

As you can see the information provided in Vragov \& Kumar (2019) contains much more detail. The word value is used instead of preference intensity in order to make the instruction clearer to the subjects. Also notice that neither of the instructions mentions the actual distribution from which the preference intensity is drawn again with the intention to not confuse the subjects.

We plan to record the vote of each experiment participant. Using the data we are then able to calculate the earnings for each individual. To express our working hypotheses more formally we expect:

WH1: $\bar{\pi}^{\text {Baseline }}>\bar{\pi}^{\text {Our Treatment }}$

where $\pi$ is the average of the total earnings of each individual in the respective treatment. We are also planning on counting the number of counterbids and overbids, and the proportion of real preference intensity that is revealed in each participant's bid.

We recruit subjects from the undergraduate population at a large urban university. When they log in during the first day of the experiment, they have to read the experiment instructions and take a quiz based on the instructions to make sure that they understand them (We borrow the instructions and the quiz from Vragov \& Kumar, 2019) Then, they can proceed to vote in the four referenda. If subjects miss to vote during an experimental day, they cannot go back and vote for that day during any of the following days. At the end of each day subjects can see their results from previous days. After the end of the experiment, subjects can come during our office hours and collect their earnings. There are 80 subjects in the Vragov \& Kumar's study and 23 subjects in our study.

\section{EXPERIMENTAL RESULTS}

Our main result is that there is no statistically significant difference in individual earnings between Vragov \& Kumar's baseline study and our study. This means that there is not enough evidence in support of our working hypothesis that earnings in the baseline are higher than earnings in a treatment with lower granularity of information about other people's preferences.

The result can ascertained by comparing the data from the baseline treatment and our treatment.. Vragov \& Kumar (2019) report 80 independent observations and we have 23 independent observations. The sample mean in the baseline is 17.18 and the sample standard deviation is 25.83 . The corresponding statistics in our study are 22.53 (the sample mean) and 20.69 (the sample standard deviation). Our initial intention has been to use one-way ANOVA but our data fails the Shapiro-Wilk test for normality, so we use the Kruskal-Wallis test for difference in medians since the two samples have similarly-shaped distributions as shown in Figure 1. The p-value under the hypothesis of no difference in medians is 0.5264 . We analyze the data further at the level of individual strategies. According to Oprea et. al. (2007) strategies that individuals use to game the system (i.e. counterbidding and overbidding) are not profitable in the long run, which means that they cannot be optimal strategies. Thus, we expect that a decrease in granularity of information about the real preference intensities of other individuals is likely to cause more suboptimal votes - or more overbidding and/or counterbidding. We test for differences in each individual's proportion of counterbids, overbids, revealed preference intensity and revealed false preference intensities. The results are shown in Table 1 and the data are plotted in Figures 2,3,4 and 5. We consistently use the Kruskal-Wallis test because all data failed Shapiro-Wilk's normality test but the distribution being compared had roughly the same shape. We found no significant differences in individual behavior based on these observed variables.

We find the results related to the first hypothesis surprising. Normally one would expect that providing more preference information to individuals will help individuals make better decisions which will lead to better earnings. This is not happening in the field experiment. One explanation for this result is that both levels of granularity: the one in the baseline treatment and the one in our treatment are not at the appropriate level to make a real difference in behavior and earnings, which suggest that further experimental work will be needed to find the level of detail at which significant differences in behavior and earnings emerge. From a purely practical viewpoint, however, the results are somewhat encouraging because they indicate that individual participants might not need a lot of information in order to participate effectively in this new 
referendum mechanism. Gathering information about other individuals' real preference intensities is costly and so the fact that having more information has no effect on results makes participation more equitable and fair since not every individual might be able to afford getting additional information.

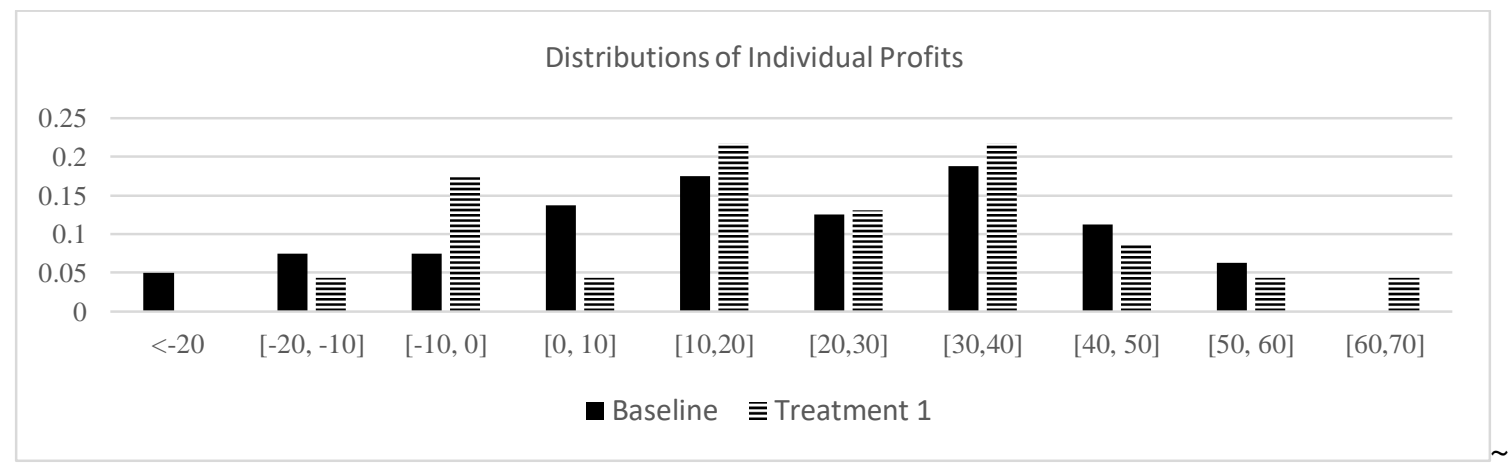

Figure 1

Table 1. Comparison of behavioral variables in the Baseline treatment with Treatment 1

\begin{tabular}{|c|c|c|c|c|c|}
\hline & Vragov & Kumar, 2019 & Current study & & \\
\hline Variable & $\begin{array}{l}\text { Sample } \\
\text { Mean }\end{array}$ & $\begin{array}{l}\text { Sample Standard } \\
\text { deviation }\end{array}$ & Sample Mean & $\begin{array}{l}\text { Sample Standard } \\
\text { Deviation }\end{array}$ & $\mathrm{p}$-value \\
\hline $\begin{array}{l}\text { Proportion of } \\
\text { Counterbids }\end{array}$ & $33.64 \%$ & $24.53 \%$ & $33.33 \%$ & $31.12 \%$ & 0.7149 \\
\hline Proportion of Overbids & $45.60 \%$ & $30.96 \%$ & $45.62 \%$ & $33.73 \%$ & 0.9526 \\
\hline $\begin{array}{l}\text { Revealed Preference } \\
\text { Intensity }\end{array}$ & 10.7 & 38.08 & 5.34 & 14.29 & 0.2517 \\
\hline $\begin{array}{l}\text { Revealed False } \\
\text { Preference Intensity }\end{array}$ & 8.45 & 23.16 & 6.32 & 18.91 & 0.3527 \\
\hline
\end{tabular}

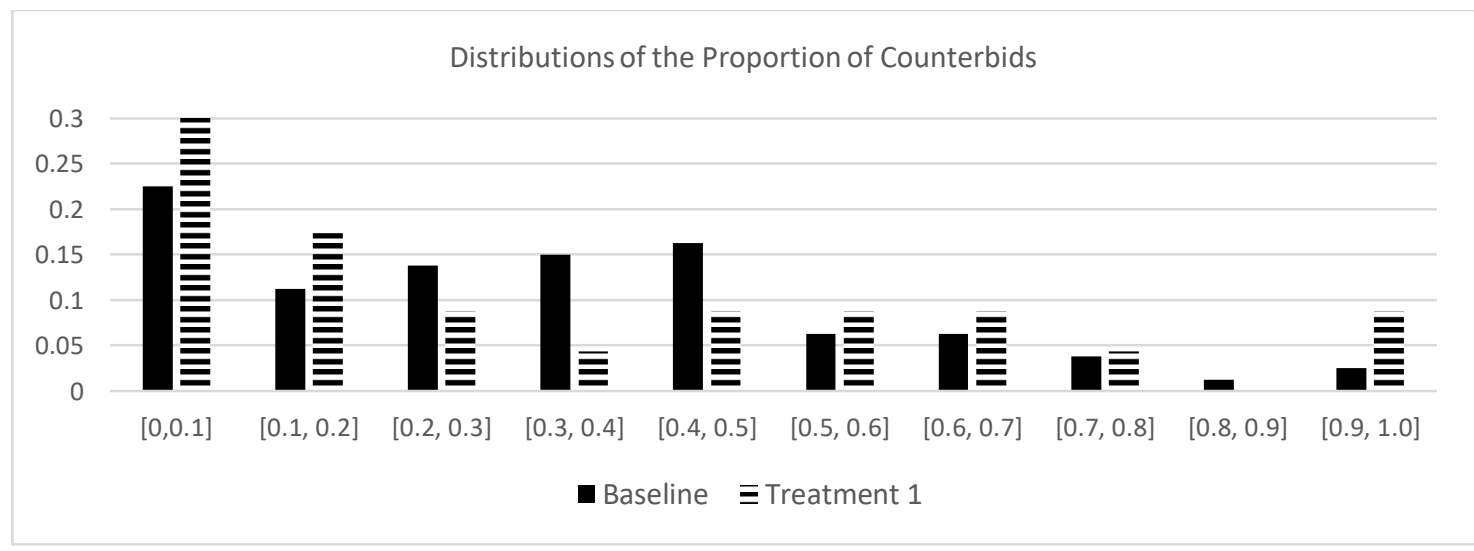

Figure 2

\section{CONCLUSIONS, LIMITATIONS, AND FUTURE RESEARCH}

The properties of a new electronic voting mechanism need to be explored thoroughly before such mechanism can be used in practice. Our experiment explores how a change in one feature of the mechanism, i.e. the granularity of the information individuals receive about the preference intensities of others, impacts the outcome of the mechanism. We find no significant effect on voting behavior and referendum outcomes. This arguably makes the referendum mechanism more practical since the referendum works just as well when voters have less information about the preferences of others which is a more common occurrence. 


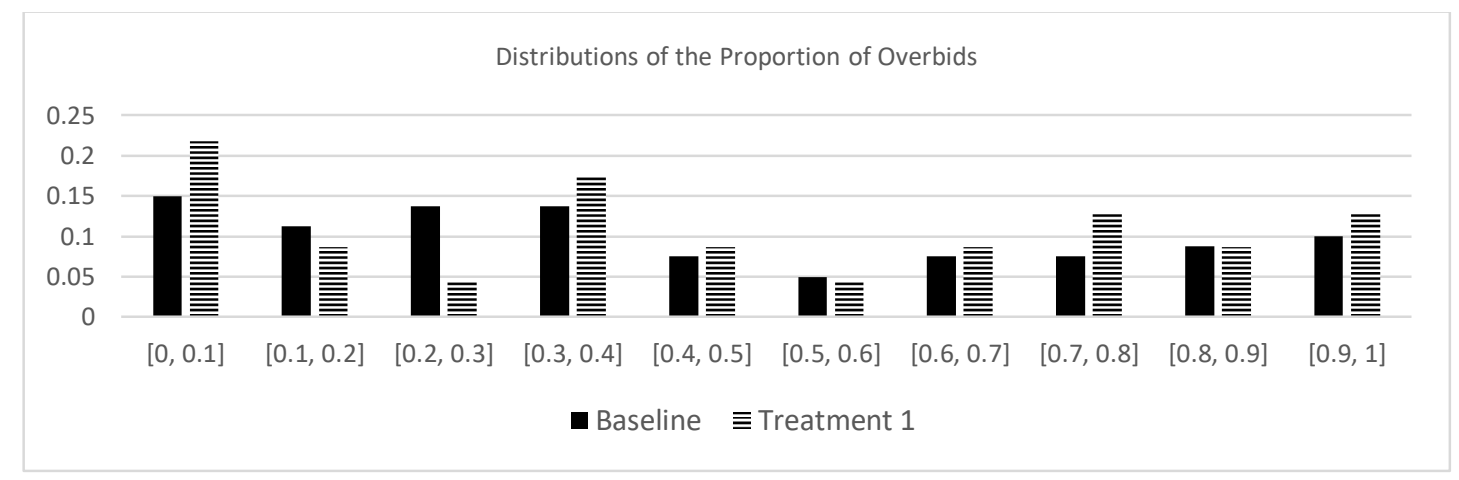

Figure 3

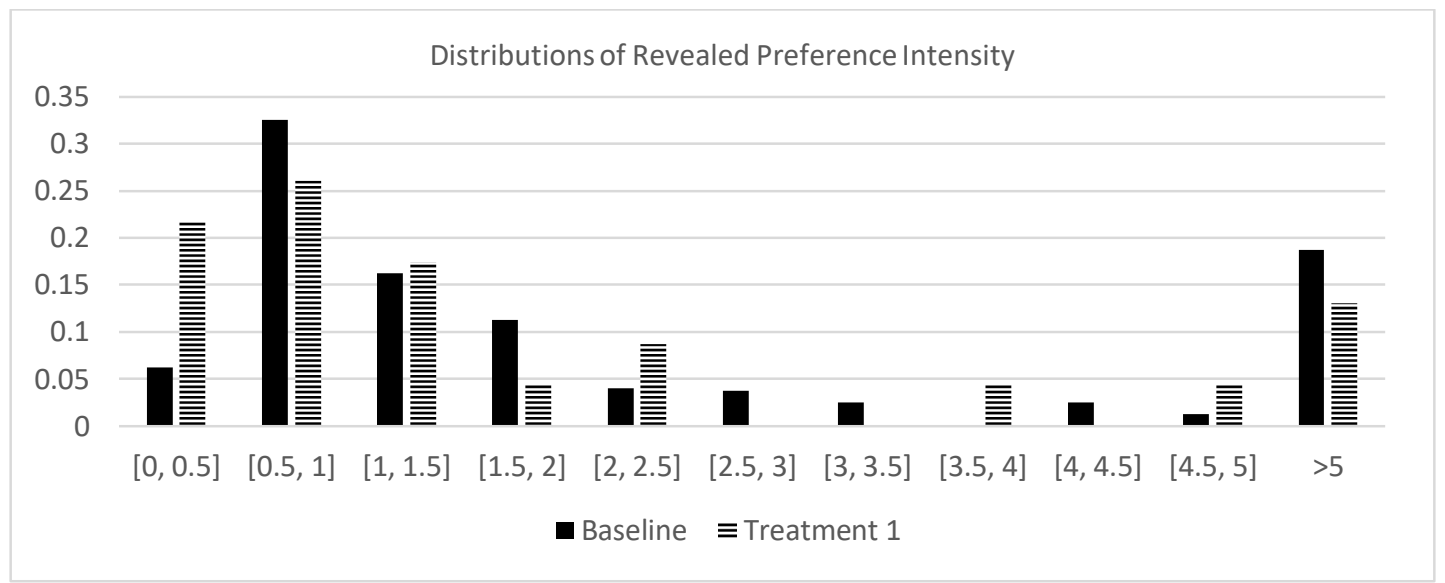

Figure 4

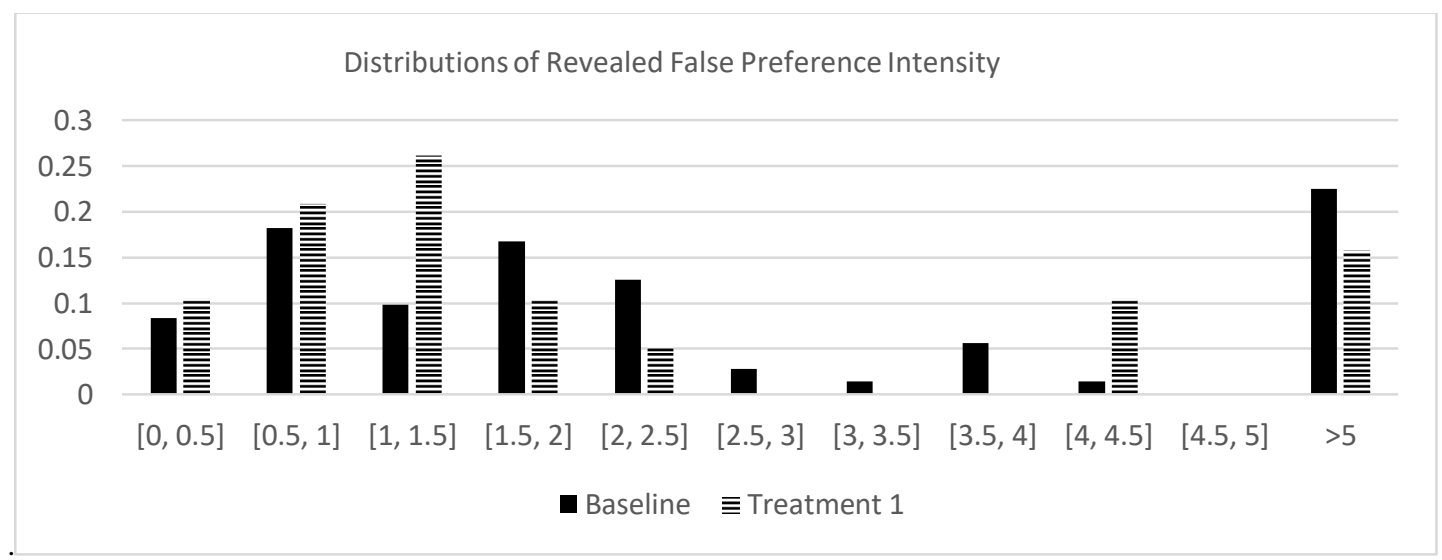

Figure 5

Our study has many limitations. Every time when one runs an experiment one has to make many operational decisions about exactly how the experiment will be conducted. In that sense it would be good to conduct experiments varying the way the information is displayed on the screen, varying the way instructions are provided to individuals, and think of ways to explore how every individual is absorbing and using the information shown on the screen. In a field experiment there are also many external variables that are not under the control of the experimenter. So even when we try our best to select similar subjects in similar environment and at a similar time. there is always a chance that an unobserved external variable has an influence over the outcome. 
The next question to answer is if inequality of available preference intensity information about others can impact participants' earnings. In our study we decreased the granularity of that information uniformly among all subjects, but in reality different participants might have unequal access to information so, some participants might have more granular information than others. Other features of the mechanism also need to be explored in more detail. Some description of preference intensities might be easier to understand by voters than others. For some people Level 2 granularity might be just easier to grasp than Level 1 granularity. One might wonder whether some voters might feel excluded due to the complexity of the setting (compared to a traditional referendum). This not only violates their democratic rights but puts the legitimacy of the referendum under question.

\section{REFERENCES}

Abelson J. et al, 2004. Transparency, Trust, and Citizen Engagement, Ottawa, Canadian Policy Research Networks Inc.

Ballou, B. et al, 2010. Creating Effective Dashboards: How companies can improve executive decision-making and board oversight Strategic Finance, v91 n1, pp. 27-33

Baltzan, P.,2017. Business Driven Technology, $6^{\text {th }}$ ed., MAcGraw Hill, New York, 2017

Banerjee, A \& Maier, P., 2016. Public Information Precision and Coordination Failure: An Experiment Journal of Accounting research, v54 n4, September 2016, pp. 941-62

Bertot, J. et al, 2010 Using ICTSs to create a culture of transparency: E-government and social media as openness and anti-corruption tools for societies Government Information Quarterly, v27 n3, pp. 264-271

Blackwell, D., 1951 Comparison of Experiments In Proceedings of the Second Berkeley Symposium in Mathematical Statistics and Probability, University of California Press, (1951): pp. 93-102.

Chengalur-S. et al, 1999 The impact of data quality information on decision-making: An exploratory analysis IEEE Transactions on Knowledge and Data Engineering, v11 n6, pp. 853-864

Dawes, S. \& Helbig, N., 2010 Information strategies for open government: Challenges and prospects for deriving public Value from government transparency" In Electronic Government pp. 50-60 Springer, 2010

Goes, P., 2013 Design science in top information systems research journals MIS Quarterly, v38 n1, pp. 3-8.

Gregor, S., 2006 The nature of theory in information systems. MIS Quarterly, v30 n3, pp. 611-642.

Hevner, A. et al,.2004 Design science in information systems research. MIS Quarterly, v28 n1, pp. 75-105.

Jenkins, A., 1985 Research methodologies and MIS research. Research methods in information systems, v103, pp. 117.

Lang, K et al, 2015 Consumer Co-creation of Digital Culture Products: Business Threat or New Opportunity? Journal of the Association for Information Systems, September 2015, v16 i9, pp. 766-798

March, S. T., \& Smith, T. F., 1995 Design and natural science research on information technology. Decision Support Systems, v15 n4, pp. 251-266.

Matheus, R. et al, 2018 Data science empowering the public: Data-driven dashboards for transparent and accountable decision-making in smart cities Government Information Quarterly, in press

Oprea, R. et al, 2007 A compensation Election for Binary Social Choice Proceedings of the National Academy of Sciences, v104 n3, January 16, 2007, pp. 1093-1096

Peffers, K. et al, 2007 A design science research methodology for information systems research Journal of Management Information Systems, v24 n3, pp. 45-77

Peng, J. et al,.2007 An Experimental Study of Multidimensional Hierarchical Accounting Data: Drill-Down Paths Can Influence Economics Decisions Journal of Information Systems, v21 n2, Fall 2007, pp. 69-86

Smith, V. L. 2004 "Buy Me Out" Forbes

Vragov, R. \& Kumar, N. 2019 Preparing the Laboratory-to-Field Transition of a New Electronic Voting Mechanism: Design Lessons from an Exploratory Semi-field Experiment" International Journal Of Electronic Government Research, v15 n4, pp. 63-89

Wicksell, K,1896 A New Principle of Just Taxation translated by J.M. Buchanan, in R.A. Musgrave and A.T. 